\title{
Research on the Training Mode of Science and Technology Innovation Talents in Applied Colleges
}

\author{
Hebin Cheng, ${ }^{1,2}$ Fang Ruan ${ }^{1,2, *}$ \\ ${ }^{1}$ School of Mechatronics, \\ ${ }^{2}$ Key Laboratory of Public Security Management Technology in Universities of Shandong (Shandong Management University) \\ Shandong Management University, \\ 250001 Jinan, China \\ ruanfang703@163.com
}

\begin{abstract}
The cultivation of innovation ability is one of the basic tasks of talents training in applied colleges. In consideration of the current situation of the innovative ability, our research was conducted from the establishment of competition platform, the construction of cultivating innovative laboratory, the cultivation of innovation ability and many other aspects. Focused on the construction of innovative ability, this paper explores the cultivation of scientific and technological innovation talents in colleges, with the introduction of enterprise elements to get an understanding of industries' needs. It has pushed forward the teaching reform and a set of initial training models come into being, which plays an important role in the cultivation of college students' innovation abilities.
\end{abstract}

Keywords-Science and technology innovation; Talent training, Innovation ability; Innovation platform

\section{INTRODUCTION}

In the era of knowledge and economy, the cultivation of college students' innovative thinking is of vital importance, which not only concerns the future competitiveness of the country, but also closely relates to their own developments. In recent years, under the macro background of national innovation education and quality education, a vast majority of college students keep pace with the times, constantly improve the quality of self-innovation and possess favorable perspective of innovation and development. But in the innovation training mode of college students, there are still many deficiencies in practice [1]. Today, the popularization of high education brought about dramatically increasing number of students, which to a certain extent accounted for increasingly prominent problem of the teachers' shortage. Some teachers devoted to heavy tasks, often with several roles on ones shoulders, which made it hard for them to spare time and energy on innovation education. Moreover, deficient professional knowledge also impeded the effectiveness of cultivating students' innovative thinking. At the same time, many universities focused most of the resources on the scale construction regardless of support construction of college students' innovation training, such as teaching equipment, training sites, software facilities, etc., relying solely on the efforts of teachers and students and the result is unsatisfactory. Influenced by the education environment, students attached too much emphasis on the education of professional knowledge, leading to the lack of initiative and active participation in the innovation of education, and their limited thought restricted innovative practice to be carried out [2].

\section{THE CURRENT SITUATION OF INNOVATIVE TALENTS TRAINING}

\section{A. Monotonous and rigid teaching mode}

In the undergraduate education stage, the teaching was mainly carried out in the form of "teaching by teachers, listening by students, and evaluation by examination", which made the students lack of enthusiasm for learning, especially for some professional courses, and lose confidence of the professional courses. Meanwhile, under this kind of education students were in the absence of active thinking, most of whom developed thinking inertia, just learned what the teacher taught and focused on what to be examined. Learning was passive, without in-depth study and thinking, problems were hard to detect, thus directly killing the active thinking, rich imagination and creativity of college students.

\section{B. Lack of ability to screen massive information}

In the wake of the continuous progress of science and technology, information technology is becoming more and more flourishing. Internet provides massive information, but students are absent from high quality of the query analysis, screening and utilization. Although the method of acquiring knowledge is more diverse, college students lack of judgment for useful information and spend a lot of time in reading useless information, the integration of information is also in short of logic and rational. 


\section{Poor motivation of students' innovative consciousness}

With the expansion of university enrollment in China, the quality of students in applied colleges has dramatically decreased. Generally, these students enrolled university with relatively low scores, many of whom were not the top students in senior schools, either the poor ones, little attention was paid on them. Therefore, in the early stage of college learning, students' self-confidence was generally not strong, coupled with the view that the science and technology innovation was supposed to belong to the research oriented college students. This caused insufficient motivation of the undergraduates' participation in scientific and technological innovation activities [3].

At present, although many students realized the importance of innovation ability, also had the desire and initiative to cultivate innovative ability, but it turned out to be not satisfactory in learning and practice. The enthusiasm of the new college students to participate in innovative activities was high, but in the high self-restraint, self-discipline, selfmanagement and independent learning environments, many students can not adhere to it. How to keep autonomous learning and self-management and stick to the teacher's plan without indulgence and abandon has become a problem of college students' sustainable autonomous learning.

\section{Weak team awareness}

Team spirit and consciousness is very important in the cultivation of innovative ability. The contemporary college students have strong self-consciousness but poor team consciousness. It is the key point that learning to communicate and deal with the problems encountered with others and relying on the team is what the students should focus on at this stage. At present, many experiments were completed independently in school education, deficient in team cooperation projects, so how to guide students to strengthen training in innovation activities is also an important task.

\section{THE CULTIVATION OF INNOVATION ABILITY AS THE FOUNDATION OF TALENT TRAINING}

\section{E. The necessity of training scientific and technological innovation ability}

Science and technology innovation ability is the requirement for talent training in the current era. With the further development of China's economic strength and the development of the economic globalization trend, enhancing the ability of technological innovation has become the main direction of the country and an important measure to enhance the comprehensive national strength. "Science and technology is the foundation of national prosperity, innovation is the soul of national progress." For the students who shouldered the historical mission, only by cultivating a high degree of innovation ability and continuous innovation in learning can they take on the historical mission of building socialist modernization and realize the great rejuvenation of the Chinese nation [4].

College students are regarded as the future of the science and technology development and charged with the task of national construction, their cultivation of innovative quality is very important. Universities as a training ground should actively respond to national call and follow the law of education development to play its role of cultivating students' innovative thinking.

\section{F. Cultivating innovative consciousness}

Ideas renewal is the basis of innovation while ideological change is the guide to innovation. The change of ideas permeated into all social things, such as innovation, study and life, so that innovation will become our conscious action and eternal theme. In practice, we broke through all the ideas impeding innovation to deal with problems in new ways and accordingly got out of the road of the conservative, rigid and natural mode of thinking [5].

\section{G. Strengthening the cultivation of innovation ability and improving the autonomous learning ability of college students}

Learning activities, in terms of the students' initiative, displayed the forms of passive acceptance, active investigation and others. To cultivate students' autonomous learning ability is to change the way of thinking and make use of the knowledge to deepen the understanding of the interest field. Through practice, students' horizons and knowledge has been broadened, their thinking and imagination has been stimulated. Improving the students' ability of self-expression and active communication with others perfected their understanding of knowledge. Innovation based on autonomous learning is the inner driving force to cultivate talents, but also the prerequisite for improving the scientific and technological innovation ability.

\section{MULTI MEASURES TO IMPROVE TALENT TRAINING ABILITY}

To improve the talent training ability, we focused on the core idea as displayed in Fig.1, and further introduced enterprise elements to establish the open, gradual education reform of talent training modes.

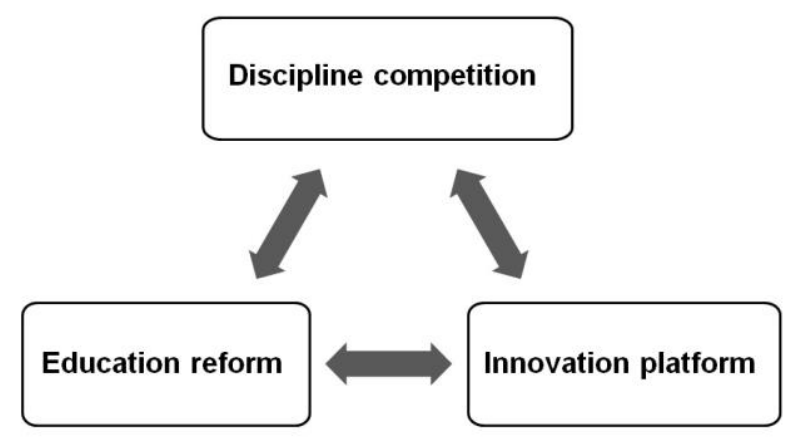

Fig. 1 Schematic diagram of core idea to improve the talent training ability. 


\section{A. Participation in high level science and technology innovation competition}

Science and technology innovation competition is gradually diversified both in types and forms. Besides the national science and technology innovation competition, the provinces and cities also followed to select high-quality events in line with professional characteristics to arrange the students of different grades and majors to participate in. In the process of organization, the promotion of students' ability in the initial stage of competition expanded the influence and appealed more students to participate in them; at the same time, the university carried out science and technology innovation contest of its own characteristics in line with the education idea, actual situation and distinguishing feature of school.

\section{B. Decomposing competition ability and promoting the teaching reform}

Teaching reform can be deepened and promoted through participation in the technology innovation competition. The knowledge and ability of deconstruction in the competition nurtured curriculum construction. The reform of curriculum practice provided a favorable practice platform for training innovative talents and extensive space for students to display their talents. Students' enthusiasm for innovative practice has been enormously stimulated by means of transforming the original theoretical learning into operational steps, refining the curriculum unit from specific events and converting the course into real-time exercises. In the past three years, through the annual scientific and technological innovation competition, teachers were supposed to improve the exercise in class. It deepened the students' understanding of theoretical knowledge and the ability to apply professional knowledge in solving practical problems. Meanwhile, students should learn how to find and analyze data, write scientific papers and enhance personal expression to comprehensively reinforce the quality of the courses.

\section{Setting up professional innovation platform}

The ability to appeal was deemed as the main line, three level progressive competition platform composed by the "general-professional basis-professional" was established for students of different grades and professional backgrounds. It made innovation throughout the training period in multi dimensions and levels, followed by the establishment of multilevel, progressive innovative practice system. As for the specific implementation, the first grade students deficient in professional foundation were intensified in cognition of mathematics, computer basis, and C language curriculum practice. We implemented the philosophy of "practice makes perfect", exerted efforts to develop their innovative ideas and encouraged participating in the "paper bridge bearing" design contest and the National College Mathematical Modeling Contest. For the second grade students who have possessed some basic professional courses selected the matching competition from professional structure, such as the MCU Application Design Contest of Shandong Province, Science and Technology Innovation Competition of Shandong Province and some others. This made students understand the knowledge application, and expand the field of vision on the basis of professional categories in the competition, learning to communicate with their peers. Moreover, some innovation platforms, such as ICAN innovation contest that judges from the enterprise, students not only got knowledge and experience in the process of participating in competitions, but also understood the demands of the industry and the development trend; for the three or four grade students with certain professional knowledge, they were devoted to high level professional competition to further enhance the professional knowledge, such as in the National Undergraduate Electronic Design Contest, the National Undergraduate smart car competition and innovation activities. This fostered their ability of practical application in hardware platform development, software programming and system debugging. As a result, every student in their 4-year college life achieved annually platform and yearly improvement. Innovation activities penetrating the whole stage of university education training met the goal of cultivating students' ability as well as maintain some freshness for students to a certain extent, which was consistent with their age characteristics and behavior habit. At the same time, innovative purposes and objectives were also brought back to school to carry out innovation activities after refining summary. It called for full participation to let more students to participate in the innovation activities.

\section{Introducing enterprise elements and understand industry demand ahead of time}

With the enrollment expansion of high education, the number of graduates annually flourished, the employment situation is very serious. College students' science and technology innovation competition, with the introduction of enterprise elements, made it not only the platform for students to display, but also a shortcut for understanding the business needs. The contest conducted and undertaken by the enterprise provided students with employment opportunities, while the enterprise also had better understanding of the basic quality and ability of college students. In innovation activity, the enterprises topics were introduced, so that through the enterprise project students can get an understanding of their own professional industry's development, the actual demand and the direction of the industry [6]. In the innovative activity, students' practical ability, psychological quality and deep thinking ability has been greatly enhanced and quickly adapt to the job after graduation.

\section{E. Establishing innovative laboratory to improve students autonomous learning ability}

Thought guides behavior, behavior consolidates thought there is an inseparable relationship between them. Therefore, universities should not only pay attention to the cultivation of innovation thinking of college students, but also establish a good practice supporting environment to promote the continuous development. In the process of specific practice, the independent innovation laboratory was established. In the light of college students' personality characteristics and interest preferences, diversified innovative practice activities were organized and relevant teachers were required to participate in examining and perfecting their achievements from a more professional perspective. Open innovation laboratory rendered students with more access to the 
laboratory to display specialties, enjoying the joy of creation, sharing experiment resources and realizing the experience inheritance and team training. The utilization efficiency of the laboratory has been improved, and the foremost is that students' innovative enthusiasm and sense of participation has been enhanced. At the same time, the guiding role of innovative teachers were given full play in innovative activities, not only in practice, but also in guiding students' continuous progress in the means of thinking and thinking framework. In recent years, a large number of students with practical ability and innovative thinking have been raised in the innovation laboratory, winning dozens of national and provincial innovation competition awards. These students were greatly received in the process of employment.

\section{CONCLUSION}

We explored the training mode reform of the integration of knowledge and ability with the innovation platform construction as the core. Moreover, we provided platforms for college innovation activities through a variety of means to stimulate the initiative of students' participation. At the same time, we integrated into the reform of classroom teaching and practice teaching and highly fused knowledge goals and occupation ability. A closed loop chain was formed with multiple measures to support the students' innovation activities and made it an empirical study in students' practice, which has practical significance for the reform of talent cultivation in applied colleges.

\section{ACKNOWLEDGMENT}

This work was financially supported by the Shandong Province Education Science "13th Five-Year" Program (BYGI2017012), Education Reform Project of Shandong Management University (JG2016-22), the Key Laboratory of Public Security Management Technology in Universities of Shandong (Shandong Management University) and 2016 Shandong Undergraduate Colleges and Universities Teaching Reform Research Project.

\section{REFERENCES}

[1] M. Chen, "Exploration on the cultivation path of innovative thinking of science and engineering college students", Industrial \& Science Tribune, vol. 16, pp. 173-174, 2016. (In Chinese)

[2] G. Zhang, X. Zhang and D. Jiang, "Exploration on the cultivation path of innovative thinking of science and engineering college students", Science \& Technology Information, vol. 5, pp. 23-24, 2014. (In Chinese)

[3] Y. Gao, J. Zhang and H. Liu, "Construction of applied talents training mode based on college students' science and technology innovation", Industrial \& Science Tribune, vol. 34, pp. 83-85, 2014. (In Chinese)

[4] W. Wang, F. Ma and X. Chen, "Top level design and target platform construction of talent training mode", Educational Research, 2011, vol. 2 pp. 58-63. (In Chinese)

[5] Y. Zheng, Z. Jiang and Y. Wu, "Implementing the innovation program of college students to lead and promote the reform of talent training mode", China Higher Education, vol. 18, pp. 37-39, 2012. (In Chinese)

[6] Z. Xiao, J. Wu, B. Shi, C. Guo and H. Li, "Research on the practice teaching mode of electronic information class undergraduate programs based on school-enterprise cooperation", Education Teaching Forum, vol. 34, pp. 43-45, 2017. (In Chinese) 